\title{
Analysis on the Evaluation of Solfeggio and Ear Training Courses
}

\author{
Chao Song \\ School of Music \\ Shaanxi Normal University \\ Xi'an, 710119, China
}

\begin{abstract}
Based on the existing problems in the evaluation of Solfeggio and ear training courses, this paper, combining the theoretical and practical significance of Solfeggio and ear training courses, analyses the basic path of evaluation of Solfeggio and ear training courses from the orientation of curriculum objectives, curriculum contents and curriculum implementation. It puts forward the thinking of "the evaluation function shifts from focusing on screening to focusing on development, the evaluation object shifts from focusing on results to focusing on process, the establishment of an evaluation concept that emphasizes both knowledge-based and experience-based, and the establishment of an evaluation concept that emphasizes both technical training and cultural attributes", aiming to analyze and study the problems existing in the evaluation of Solfeggio and ear training courses, and to reveal the fundamental value and significance of Solfeggio and ear training courses.
\end{abstract}

Keywords-Solfeggio and ear training; course evaluation; path; thinking

\section{INTRODUCTION}

Solfeggio and ear training, as a basic discipline in the field of music education, has both theoretical and technical characteristics. It intersects and penetrates with many disciplines in music. For a long time, solfeggio and ear training has been regarded as a course for the purpose of music reading. Through music auditory training, trainees have the ability to identify the basic elements of music and to grasp the relationship between the voices of music works. In the new round of teaching reform, many scholars gradually break through the old understanding of the teaching purpose, beyond the long-focused relationship between solfeggio and ear training course and teaching, and begin to pay attention to the relationship between solfeggio and ear training course itself and evaluation.

\section{Problem Existed in Solfeggio And EAR Training COURSE EVALUATION}

From the perspective of curriculum theory, curriculum evaluation and curriculum objectives, curriculum content and curriculum implementation constitute the four elements of curriculum as a whole. As an important part of the whole curriculum, curriculum evaluation is used to determine whether the objectives are achieved. Its fundamental purpose is to ensure the scientificity and rationality of teaching activities, and to provide the basis for the adjustment of curriculum objectives, curriculum content and curriculum implementation.

In his monograph Solfeggio and ear Training Pedagogy, Mr. Wang Guangyao argues that the basic task of Solfeggio and ear training is to organize and develop students' musical hearing and train them to actively apply it to creative and performing practice. [1]Re-recognizing the teaching function of solfeggio and ear training, Ms. Chen Yaxian pointed out in the Solfeggio and Ear Training Teaching Theory: "The essential function of education and teaching of solfeggio and ear training is to cultivate and improve the externalization form of people's music exchanges, and to cultivate other kinds of human abilities in a subtle and efficient way, to realize the value of their educational value, entertainment value and the transmission of music culture. And this is the foundation of the education and teaching of solfeggio and ear training."[2]

Different understanding of the function of curriculum will lead to different evaluation criteria. Similarly, in the actual curriculum evaluation, different teaching content will also come up with different evaluation criteria, and the evaluation results will have different effects on the teaching content. In the current evaluation system of Solfeggio and ear training courses, there are still several problems to be solved urgently.

\section{A. Over-focus on evaluation results}

In the solfeggio and ear training evaluation system, students' test scores seem to be the standard for judging students' learning. Teachers only care about test scores and ignore the generative factors of the teaching process.

\section{B. Single evaluation subject}

The evaluation subject is not just a student, but should be the participation of teachers, textbooks and other aspects related to teaching. The current curriculum evaluation ignores the evaluation of teachers and teaching materials, especially the self-evaluation of students, which leads to the uneven learning efficiency of learning subjects.

\section{One-sided evaluation criteria}

If the evaluation criteria are too mechanical and single, students' personality development and individual differences will be neglected. In the common Solfeggio and ear training examinations, most colleges and universities adopt the form of auditory written examination and audiovisual oral examination, 
but only these two examinations can't fully reflect the strengths and abilities of students.

\section{The BASIC PATH OF THE Evaluation Of SOlFEgGiO AND EAR TRAINING COURSES}

The evaluation of solfeggio and ear training requires a certain way to judge the value or characteristics of solfeggio and ear training curriculum, teaching plans, teaching activities and their results in a certain way. From the perspective of development, the establishment of a scientific, complete and unified evaluation system of Solfeggio and ear training courses and the comprehensive, scientific and objective evaluation of courses are the means to ensure that teaching decisions do not deviate and achieve educational goals.

\section{A. Evaluate from the course goal orientation}

Curriculum objective is not only the guide of teaching activities and educational work, but also the criterion to measure the quality of curriculum. The choice of Solfeggio and ear training curriculum objectives should be based on the premise that students acquire certain basic knowledge, and strengthen horizontal links with other disciplines, so as to improve students' musical literacy and good emotional values. However, students' needs, social needs and discipline development, as the three elements of curriculum objectives, have different orientations, which will lead to different value orientations of objectives. "No goal system is a single center of students, society or disciplines." [3] They are indispensable and cannot exist without each other. Therefore, when evaluating the objectives of Solfeggio and ear training courses, we should take both into account. First, we should take promoting students' development as the fundamental purpose to carry out evaluation activities.

As the main body of learning, students should take "students' needs" as the first step of evaluation. Therefore, in the evaluation of Solfeggio and ear training curriculum objectives, "what to learn" and "how to learn" should be the focus of evaluation.

The solfeggio and ear training courses have always been composed of two parts: solfeggio and ear training. The understanding of this subject is mostly at the level of listening and singing, so that it is considered that: solfeggio is the vocal music, ear training is the notation. As a basic subject in the field of music education, solfeggio and ear training, both theoretical and technical, require students to combine basic theory with practical music learning, and infiltrate the use of basic music theory into the training of musical auditory thinking.

In the process of teaching, teachers should also adopt heuristic teaching to enable students to use their knowledge creatively and actively participate in learning activities, so as to promote Solfeggio and ear training disciplines to give full play to their own disciplinary characteristics, better serve other disciplines and cultivate diversified talents with innovative abilities to meet the social needs of the new era. The objectives of Solfeggio and ear training course not only have the characteristics of the subject itself, but also have the commonness of other courses. It does not adhere to the goal of musical knowledge and skills, and emphasizes the development of musical perception, appreciation, expression and creativity. [4]

\section{B. Evaluate from the course content orientation}

Curriculum content is the core of teaching. The knowledge learnt by students in class is called curriculum content. Different understandings of curriculum content will lead to different views on education. Teachers' primary task in teaching activities is to impart knowledge to students, which is mainly based on textbooks and prescribed curriculum syllabus It has a certain systematicness and planning. It not only clarifies the teaching content of teachers, but also enables students to master the necessary knowledge and skills. In the evaluation of Solfeggio and ear training curriculum content, the evaluation of syllabus and textbook content should be the main aspect. How to choose the textbooks that can't only fulfill the teaching task but also enhance the learning interest for students around the reasonable syllabus is the focus of the curriculum content.

The teaching content based on learning activities is also very important. The "activity" here refers not only to the practice in class, but also to the accumulation of sufficient teaching experience for students in their future work. Through a series of activities, students' initiative and enthusiasm in learning can be effectively improved. Activity content is the course content, which aims to observe the implicit thinking operation of students through the explicit behavior of activities, and then complete teaching efficiently.

\section{Evaluate from the curriculum implementation orientation}

The process of putting teaching objectives into practice is called curriculum implementation. In this process, curriculum implementation and teaching belong to two different research categories, but there are inherent links. Teaching mainly refers to the interaction between teachers and students. Without Solfeggio and ear training, Solfeggio and ear training can't be implemented. The content of curriculum implementation is broader than that of curriculum teaching. Therefore, evaluating the implementation of Solfeggio and ear training will help to open up ideas for Solfeggio and ear training teaching and provide more useful experience for future teaching.

Firstly, scientific teaching strategies and correct implementation methods contribute to the effective implementation of curriculum. Usually, the more perfect the curriculum objectives and content are, the better the teaching effect of teachers will be. However, if there is no scientific teaching strategy and correct implementation method, the teaching effect will be greatly reduced, which can neither reflect the objective value of the curriculum nor promote the development of students' subjectivity.

Secondly, the diversified teaching mode is also helpful to the effective promotion of curriculum implementation. The traditional teaching method has always been the "lectureacceptance" teaching mode. Under this teaching mode, the main body of teaching is the teacher, while the students are in the position of passive acceptance of knowledge, and their 
subjective consciousness is not strong. Solfeggio and ear training are mostly oriented towards instrumental rational goals, unilaterally emphasizing the development of auditory skills, ignoring the functional characteristics of "diversification" and "practicality" of abilities and single teaching mode. Therefore, in the course implementation of Solfeggio and ear training, we should not only change the teaching concept, but also improve the teaching methods, train students with guidance and heuristic teaching, encourage students to participate actively and innovate boldly. We should not only to "teach-accept", but also to "guide-use".

\section{REFLECTIONS ON THE EVALUATION OF SOLFEGGIO AND EAR TRAINING COURSES}

\section{A. Evaluation function shifts from focusing on development to focusing on development}

In the traditional education evaluation system, the function of screening and selection is overemphasized, while the function of motivation is neglected.

Because of the differences in learning background, learning ability and learning time, some students with average aptitude will become "losers". Students with low evaluation are prone to conflict in evaluation activities. These students do not realize the pleasure and encouragement brought by success, so they may choose to escape in the learning process, and the improvement and implementation of the evaluation can't be mentioned. But this is not the original intention of our evaluation. Because overemphasizing the disadvantage of screening function will break the balance between instrumental rationality and value rationality, leading teachers to think only about how to teach students' skills, ignoring the cultural transmission with hearing as the carrier.

\section{B. Evaluation object turns from the attention result to the attention process}

As mentioned above, the traditional evaluation of education focuses on screening and selection, so it pays more attention to the results of educational activities and ignores the process of teaching activities.

Evaluation activities that focus only on results are actually concerns about the "past" learning situation of students and are not conducive to the promotion of future development. One of the reasons is that in most cases, teachers pay more attention to students' learning outcomes. Therefore, in the concept of curriculum evaluation reform, the evaluation object should shift from focusing on the attention process, promoting the "result" by paying attention to the "process", and focusing the evaluation on the "process" to achieve the purpose of promoting the balanced development of students' professionalism.

\section{Establishing an evaluation view that emphasizes both the knowledge standard and the experience standard}

Knowledge-based is a way of knowledge selection, which means paying special attention to the logic and structure of discipline itself in knowledge selection. In the teaching of Solfeggio and ear training, curriculum evaluation under the quantitative paradigm is a popular means and method aiming at the specialization and standardization of Solfeggio and ear training technology. The subject of evaluation is teachers, and the object of evaluation is music theory knowledge, auditory technology, etc. While students, as the main body of learning, have become neglected groups. Famous educator Taylor pointed out: "It is necessary to construct a variety of situations so that they can arouse the desired experience in all students, or to diversify the experience so as to provide some experience that is likely to be important to every student in the class." [5] Taylor's learning experience is the result of the interaction of knowledge, students, teachers and environment.

In the selection of Solfeggio and ear training curriculum content, teachers should try their best to design curriculum content to provide students with meaningful experience. From the perspective of historical development, knowledge-based education equates imparting empirical knowledge with education itself. In terms of teaching, the cramming teaching method pays no attention to students' experience, nor to the cultivation of students' practical, imaginative and innovative abilities. The experience-based curriculum concept should not only consider the learners' ultimate experience, but also the process of learners' experience acquisition.

\section{Establishing an evaluation concept that emphasizes both technical training and cultural attributes}

At present, the connotation and extension of Solfeggio and ear training courses are in urgent need of surpassing the old understanding and getting a new orientation in the new era. Solfeggio and ear training teaching is not only highly technical, but also worth exploring the cultural attributes of its curriculum. Culture is the root of curriculum. Without culture, curriculum will become passive water. Human beings condense the essence of culture in the curriculum, and the curriculum has become the main component of the national cultural inheritance.

In the decades since the founding of the country, the solfeggio and ear training discipline has been increasingly integrated into China's outstanding national music culture in the process of continuous development of teaching materials. They not only constitute the "raw material" of the teaching content of solfeggio and ear training, but also provide an inexhaustible source for the multi-construction of musical hearing in the subtle. Our multi-ethnic music is precisely because of the local language customs, geographical environment, living habits and other aspects of the impact; it has formed a unique and irreplaceable music style. In the process of teaching, we should attach importance to the national music and the aesthetic psychology of Chinese people, and do not regard "technology" as the only evaluation criterion of classroom teaching.

\section{CONCLUSION}

The solfeggio and ear training courses play a pivotal role in the entire higher music education and is the key to verifying that the basic knowledge is firmly grasped. Therefore, the solfeggio and ear training courses need to be guided and supported by scientific and rational curriculum evaluation 
concepts. At present, the course evaluation orientation of solfeggio and ear training is still not perfect. If the only yardstick is achievement, the evaluation system is too onesided. The single evaluation result can't reflect the validity, and the lag of teaching evaluation will affect the development of the whole Solfeggio and ear training discipline. This paper attempts to evaluate the reliability and validity of curriculum objectives, curriculum content and curriculum implementation. Solfeggio and ear training curriculum evaluation are put into practice to test their comprehensive functions of judging, discovering and promoting value.

\section{REFERENCES}

[1] Wang Guangyao. Solfeggio and Ear Training Pedagogy Collection [M] Xi'an: Taibai Literature and Art Publishing House, 2014.

[2] Chen Yaxian. The Teaching Theory of Solfeggio and Ear Training [M]. Shanghai: Shanghai Music Publishing House, 2006.

[3] Han Hui. Evaluation Contents, Standards and Strategies of Curriculum Objectives [J]. Contemporary Education Forum, 2008 (6).

[4] Wang Xiuping. The Value Orientation of Music Courses[J]. Chinese Musicology, 2004(1).

[5] Taylor. The Basic Principles of Curriculum and Teaching [M]. Beijing: China Light Industry Press, 2014. 